VEREY M. 2017. Teoretyczna analiza i praktyczne konsekwencje przyjęcia modelowej siatki ATPOL jako
odwzorowania stożkowego definiującego konwersję współrzędnych płaskich na elipsoidę WGS 84.
- Fragmenta Floristica et Geobotanica Polonica 24(2): 469-488.

WoŁKowycki D. \& PAWLIKowski P. 2016. Zagrożone i chronione gatunki roślin naczyniowych w Puszczy Rominckiej (NE Polska). - Fragmenta Floristica et Geobotanica Polonica 23(1): 13-28

ZAJĄC A. 1978. Założenia metodyczne „Atlasu rozmieszczenia roślin naczyniowych Polski”. - Wiadomości Botaniczne 22(3): 145-155.

ZająC A. \& ZająC M. (red.). 2001. Atlas rozmieszczenia roślin naczyniowych w Polsce. s. xii + 714. Pracownia Chorologii Komputerowej Instytutu Botaniki Uniwersytetu Jagiellońskiego, Kraków.

Pawee Pawlikowski, Zakład Ekologii Roślin i Ochrony Środowiska, Instytut Botaniki, Wydziat Biologii, Centrum Nauk Biologiczno-Chemicznych, Uniwersytet Warszawski, ul. Żwirki i Wigury 101,02-096 Warszawa, Polska; e-mail p.pawlikowski@uw.edu.pl

Wptynęto: 20.11.2019 r.; przyjęto do druku: 17.12.2020 r.

DOI: https://doi.org/10.35535/ffgp-2020-0040

\title{
Dryopteris cambrensis (Dryopteridaceae) w Polsce południowej
}

Grupa Dryopteris affinis reprezentowana jest na świecie przez siedem gatunków: D. affinis (Lowe) Fraser-Jenk., D. borreri (Newman) Newman ex Oberh. \& Tavel, D. cambrensis (Fraser-Jenk.) Beitel \& W. R. Buck, D. pseudodisjuncta (Tavel ex Fraser-Jenk.) FraserJenk., D. schorapanesis Askerov, D. pontica (Fraser-Jenk.) Fraser-Jenk. i D. lacunosa S. Jess., Zenner, Ch. Stark \& Bujnoch (FrASER-Jenkins 2007; JESSEN i in. 2011; AsKerov $i$ in. 2015; Asgarov i in. 2016; Askerov \& AKCAY 2016). Na obszarze Polski dotychczas stwierdzono występowanie $D$. affinis, $D$. borreri, $D$. cambrensis i $D$. pseudodisjuncta (Woziwoda 2006a, b, c, 2007, 2010; SZCZEŚSIAK i in. 2009; PODSIEDLIK 2009, 2010; WilCZEK \& ZARZYCKI 2013; TLAŁKA 2015; ZARZYCKI i in. 2015; VADADZE i in. 2016). W ostatnim czasie opisano nowe dla nauki taksony związane z tą grupą: $D$. affinis subsp. cluthensis A. R. Church czy D. ×complexa Fraser-Jenk. nothosubsp. transsilvanica Tlałka, S. Jess., A. Rostański \& Rojek (Church i in. 2019; TlaŁkA 2019).

W obrębie gatunku Dryopteris cambrensis wyróżniane są cztery podgatunki: D. cambrensis subsp. cambrensis, D. cambrensis subsp. distans (Viv.) Fraser-Jenk., D. cambrensis subsp. insubrica (Oberh. \& Tavel ex Fraser-Jenk.) Fraser-Jenk. i D. cambrensis subsp. pseudocomplexa Fraser-Jenk. Podgatunki różnią się występowaniem lub brakiem wyraźnych ząbków na szczycie odcinków drugiego rzędu liści oraz kolorem łusek ogonków liściowych. Natomiast wspólną cechą podgatunków D. cambrensis są u-kształtne odcinki drugiego rzędu i duże kupki zarodni.

Dryopteris cambrensis obejmuje swym zasięgiem Europę północną, zachodnią, środkową i południową, od Norwegii po Portugalię i Bułgarię oraz Azję Zachodnią (Turcja) (FrASER-JENKINS 2007; TREWREN i in. 2014). W Europie D. cambrensis należy do grupy taksonów najmniejszej uwagi - LC (GARCÍA CRIDO i in. 2017). 
Dryopteris cambrensis w naszym kraju dotychczas została podana z sześciu stanowisk: Pstrążna w Górach Stołowych (EKRT i in. 2009), Dobków-Julianów na Wysoczyźnie Łaskiej (Woziwoda 2009; Woziwoda \& Podsiedlik 2010), Bygdoszcz w Kotlinie Toruńskiej, rew. Fraser-Jenkins C. R. (inf. ustna), Bujakowski Groń (na północno-wschodnim stoku), Groniczki (na południowo-zachodnim stoku) i Hrobacza Łąka (na wschodnim stoku) w Beskidzie Małym (TlaŁKa 2011; TlaŁKa i in. 2019). Opublikowane stanowiska z północnego stoku Bujakowskiego Gronia i południowo-wschodniego stoku Nowego Świata w Beskidzie Małym (TlaŁKa 2011) nie należą do D. cambrensis (okazy z tych stanowisk zostały błędnie oznaczone, co dowiodła późniejsza rewizja D. Tlałki). Dryopteris cambrensis występuje w podgórskich lasach iglastych i liściastych, rzadko schodzi na niż.

Badania prowadzone przez autorów w latach 2010-2018 wykazały występowanie Dryopteris cambrensis na 29 stanowiskach w południowej Polsce. Stanowiska podane z Beskidu Małego (TlatKa 2011; TlaŁKa i in. 2019) oraz nowo znalezione należą do podgatunku D. cambrensis subsp. insubrica. Wskazuje na to analiza cech morfologicznych - odcinki 2. rzędu liści z wyraźnymi ząbkami na szczycie oraz czerwonawo-brązowe łuski. Nowe stanowiska $D$. cambrensis znajdują się głównie w reglu dolnym, rzadziej na pogórzu, w zbiorowiskach boru jodłowo-świerkowego, buczyny i jaworzyny. Populacje liczą głównie kilka (np. Bujakowski Groń, DF9402; Jawornica, DF9522 w Beskidzie Małym) lub kilkadziesiąt

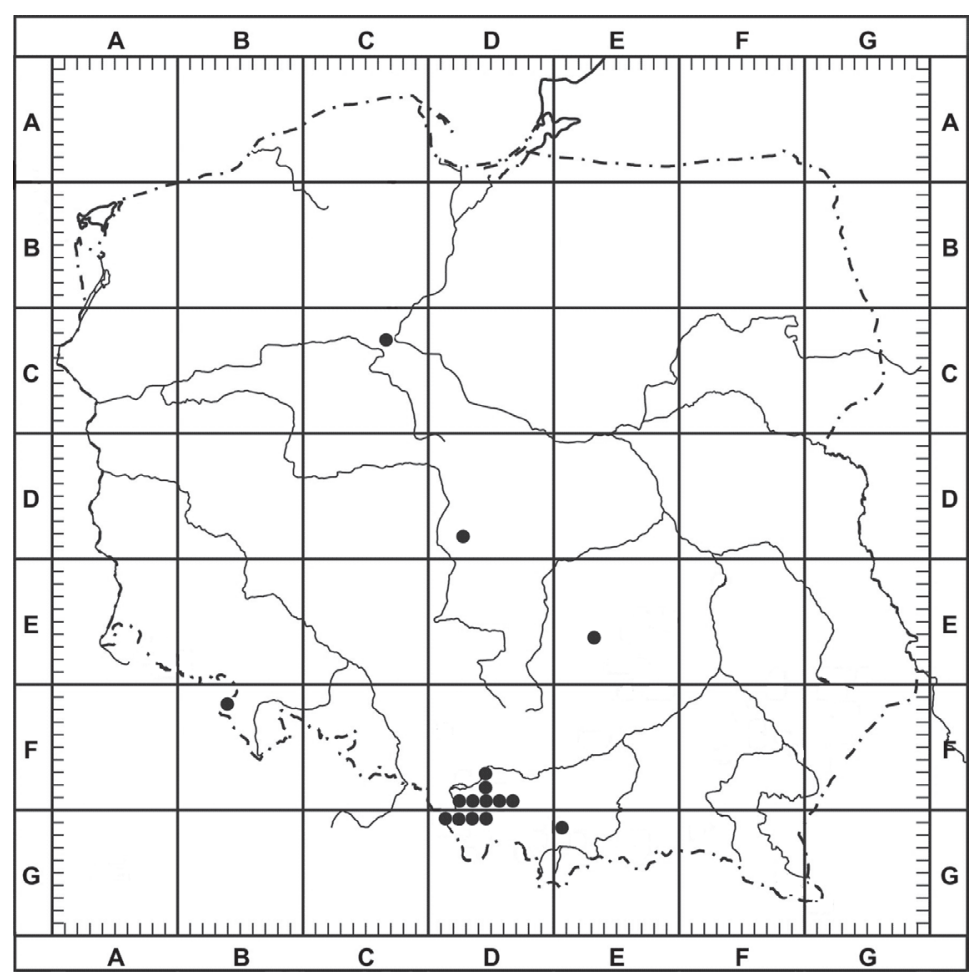

Ryc. 1. Rozmieszczenie Dryopteris cambrensis w Polsce

Fig. 1. Distribution of Dryopteris cambrensis in Poland 
(np. Szyndzielnia, DF9244 w Beskidzie Śląskim; Złota Góra, DF9511 w Beskidzie Małym), rzadko kilkaset osobników (Hrobacza Łąka, DF9411 i Groniczki, DF9420 w Beskidzie Małym).

\section{WyKaZ NOWyCh STANOWisk DRYOPTERIS CAMBRENSIS W POŁUDNIOWEJ Polsce}

Rozmieszczenie Dryopteris cambrensis w Polsce przedstawiono na rycinie 1. Mapa została stworzona w oparciu o system kartogramu ATPOL o boku 10 km (ZAJĄC \& ZAJĄC 2001). Stanowiska na Płaskowyżu Suchedniowskim (EE6304) oraz w Beskidzie Śląskim (DG0330) zostały znalezione przez Marka Podsiedlika, wszystkie pozostałe - przez Dariusza Tlałkę.

Płaskowyż Suchedniowski - EE6304: Ćmińsk Rządowy, dolina rzeki Bobrzy, w łęgu, 270 m, 2010 r.; Dolina Górnej Wisły - DF7441: Dolina Soły w Bielanach na północny-zachód od centrum Bielan, w grądzie z domieszką sosny, 260 m, 2015 r.; Pogórze Śląskie - DF8441: Kęty Podlesie na wschód od Młynka, na zrębie sosnowym, 310 m, 2010 r.; Beskid Śląski - DF9244: Szyndzielnia na północnym stoku, w lesie świerkowo-jaworowym, 620-640 m, 2014 r.; Beskid Mały - DF9314: Gaiki na północnym stoku i Groniczki na zachodnim stoku, w jaworzynie, 560-580 m, 2013 r.; DF9333: Łysa Góra na północno-wschodnim stoku, w jaworzynie, 500 m, 2017 r.; Beskid Śląski - DF9340: Kołowrót na północno-wschodnim stoku, w buczynie, 520 m, 2014 r.; Beskid Mały - DF9410: Hrobacza Łąka na południowym stoku, w buczynie, $620 \mathrm{~m}, 2011 \mathrm{r}$; DF9413: Palenica na północno-zachodnim stoku, w borze jodłowo-świerkowo-modrzewiowym, 490-550 m, 2012 r.; DF9420: Groniczki na południowym stoku, w jaworzynie, 690-710 m, 2013 r.; DF9424: Kiczera na północno-wschodnim stoku, w jaworzynie, 460 m, 2012 r.; DF9434: Kiczera na wschodnim stoku, w buczynie, 530 m, 2015 r.; DF9510: Złota Góra na południowo-wschodnim stoku, w jaworzynie, 560 m, 2011 r.; DF9511: Złota Góra na północno-wschodnim stoku, w borze jodłowym, 510 m, 2010 r.; DF9512: między Targanicami a Sułkowicami na wschód od Frydli, w borze jodłowym, 470 m, 2011 r.; DF9522: Jawornica na północno-zachodnim stoku, w borze świerkowo-jodłowym, 740 m, 2017 r.; DF9524: Gancarz na północno-zachodnim stoku, w borze świerkowym, 610 m, 2012 r.; DF9530: Góra Kocierz na północno-wschodnim stoku, w buczynie, 590 m, 2018 r.; DF9542: Kiczora na północno-zachodnim stoku, w buczynie, 630 m, 2018 r.; DF9630: Leskowiec na północno-zachodnim stoku, w borze daglezjowym, 600-610 m, 2017 r.; Beskid Śląski - DG0132: Mała Czantoria na wschodnim stoku, w borze świerkowym z domieszką jaworu, 560-570 m, 2017 r.; DG0203: Stołów na północno-zachodnim stoku, w lesie bukowo-jaworowym, 670 m, 2015 r.; DG0233: Kotarz na wschodnim stoku, w buczynie, 760 m, 2016 r.; DG0330: Szczyrk, północny stok góry Palenicy, w borze jodłowo-świerkowym, 580 m, 2017 r.; Beskid Mały - DG0400: Wieśnik na północno-zachodnim stoku, w borze jodłowo-świerkowym, 570 m, 2015 r.; Beskid Wyspowy - EG1000: Luboń Wielki na południowo-zachodnim stoku, w borze jodłowo-świerkowym, $800 \mathrm{~m}, 2010 \mathrm{r}$.

Badania prowadzone przez autorów w południowej Polsce (w Beskidzie Małym, w Beskidzie Śląskim i na Płaskowyżu Suchedniowskim) wykazały, że Dryopteris cambrensis ma w naszym kraju znacznie więcej stanowisk niż dotychczas znane, a w samym Beskidzie Małym jest niezbyt częsty. Należy kontynuować poszukiwania kolejnych stanowisk $D$. cambrensis w celu pełniejszego poznania rozmieszczenia tego gatunku w Polsce.

Summary. Dryopteris cambrensis (Dryopteridaceae) in southern Poland. Dryopteris cambrensis (Fraser-Jenk.) Beitel \& W. R. Buck is distinguished as four subspecies: D. cambrensis subsp. cambrensis, D. cambrensis subsp. distans (Viv.) Fraser-Jenk., D. cambrensis subsp. insubrica (Oberh. \& Tavel ex Fraser-Jenk.) Fraser-Jenk. and D. cambrensis subsp. pseudocomplexa Fraser-Jenk. This species was earlier recorded from six localities in Poland. In 2010-2018, D. cambrensis was discovered at 29 localities in southern Poland. Its distribution is presented in the ATPOL cartogram system $(2 \times 2 \mathrm{~km}$ grid squares; Fig. 1). All localities in Poland are of D. cambrensis subsp. insubrica. 


\section{LITERATURA}

Asgarov A., Aкchay U. \& Salimov R. 2016. New taxa of fern (Dryopteris Adans. s. str.) spread over Azerbaijan Republic. - Young Scientist USA 6: 3-8.

Askerov A. M. \& AKCAY U. 2016. About the status of certain species of Dryopteris Adans. s. str. in the flora of Azerbaijan. - Turczaninowia 19(1): 79-86.

Askerov A., AkCay U. \& Verdiyeva L. N. 2015. Taxonomic review of the genus Dryopteris Adans. s. str in Azerbaijan. - News of Azerbaijan ANAS, Biological Series 70(2): 129-135.

Church A. R., Evans A. J., Golding R., Rumsey F. J \& Viane R. L. L. 2019. Dryopteris affinis subsp. cluthensis: a new taxon in the Dryopteris affinis complex (Dryopteridaceae). - Fern Gazette 21(2): 87-97.

Ekrt L., Trávníček P., Jarolímowá V., Vít P. \& Urfus T. 2009. Genome size and morphology of the Dryopteris affinis group in Central Europe. - Preslia 81: 261-280.

Fraser-Jenkins C. R. 2007. The species and subspecies in the Dryopteris affinis group. - Fern Gazette 18(1): 1-26.

García Crido M., Väre H., Nieto A., Elias R., B. Dyer R., Ivanenko Y., Ivanova D., Lansdown J., Molina J. A., Rouhan G., Rumsey F., Troia A., Vbra J. \& Christenhusz M. J. M. 2017. European Red list of lycopods and ferns. s. iv+ 59. IUCN, Brussles.

Jessen S., Bujnoch W., Zenner G. \& Stark C. 2011. Dryopteris lacunosa - eine neue Art des Dryopteris-affinis Aggregats (Dryopteridaceae, Pteridophyta). - Kochia 5: 9-31.

Podsiedlik M. 2009. New localities of Dryopteris affinis agg. (Dryopteridaceae) in the Kielecka Upland (south-eastern Poland). - W: E. SzCZÉŚ́NIAK \& E. Gola (red.), Genus Dryopteris Adans. in Poland, s. 61-68. Polish Botanical Society, Institute of Plant Biology, University of Wrocław, Wrocław.

PoDsiedLIK M. 2010. Zmienność morfologiczna i ekologiczna gatunków z kompleksu nerecznicy mocnej Dryopteris affinis (Lowe) Fraser-Jenkins w Górach Świętokrzyskich i na Płaskowyżu Suchedniowskim. Mskr. pracy magisterskiej, Instytut Ekologii i Ochrony Środowiska, Uniwersytet Łódzki.

SzCZéśniak E., TląKa D. \& Rostański A. 2009. Key to identification and descriptions of species of Bucker-ferns (Dryopteris Adans.) occuring in Poland. - W: E. SzczÉśniaK \& E. Gola (red.), Genus Dryopteris Adans. in Poland, s. 5-34. Polish Botanical Society, Institute of Plant Biology, University of Wrocław, Wrocław.

TLaŁKa D. 2011. Nerecznica Borrera i nerecznica walijska w województwie śląskim. - Przyroda Górnego Śląska 65: 3.

TLaŁKa D. 2015. Dryopteris affinis (Lowe) Fraser-Jenk. s. str. i D. psedodisjuncta (Tavel ex Fraser-Jenk.) Fraser-Jenk. - nowe gatunki we florze Polski. - Acta Botanica Silesiaca 11: 173-182.

Tląka D., Jessen S., Rostański A. \& RoJeK M. 2019. Dryopteris $\times$ complexa nothosubsp. transsilvanica: a new hybrid from the Carpathians (Dryopteridaceae, Polypodiophytina). - Fern Gazette 21(1): 23-34.

Trewren K., Pigott A. C. \& Evans A. J. 2014. Some taxa within the Dryopteris affinis complex: a field guide. - Special Publication British Pteridological Society 13: vi +48.

Vadadze T. T., Memiadze N. V. \& Dolidze K. G. 2016. Rare ferns of Ajarian flora. - Modern problems of science and education 5: $1-7$.

WILCZEK Z. \& ZARZYCKI W. 2013. Szata roślinna rezerwatu przyrody „Dolina Łańskiego Potoku” na Pogórzu Śląskim (Karpaty Zachodnie). - Chrońmy Przyrodę Ojczystą 69(4): 322-329.

Woziwoda B. \& Podsiedlik M. 2010. Diversity of ferns from the Dryopteris affinis complex in Central Poland. - Acta Societatis Botanicorum Poloniae 79 Suppl. 1: 116-117.

WozIwoda B. 2006a. Nowe stanowiska Dryopteris affinis (Aspidiaceae) w Polsce Środkowej. - Fragmenta Floristica et Geobotanica Polonica 13(1): 218-221. 
WoziwoDA B. 2006b. Różnorodność florystyczna różnowiekowych lasów izolowanych w krajobrazie rolniczym Polski Środkowej, a problem zachowania i ochrony rodzimych gatunków leśnych. - Studia i Materiały Centrum Edukacji Przyrodniczo-Leśnej w Rogowie 11: 103-109.

WozIwodA B. 2006c. Inwentaryzacja flory roślin naczyniowych w lasach Nadleśnictwa Poddębice (RDLP Łódź). - Studia i Materiały Centrum Edukacji Przyrodniczo-Leśnej w Rogowie 14: 115-125.

Woziwoda B. 2007. Flora lasu szadkowskiego. - Biuletyn Szadkowski 7: 185-195.

Woziwoda B. 2009. Morphological diversity of ferns in the Dryopteris affinis group in Central Poland. - W: E. SzCŹ̨̧ŚniaK \& E. Gola (red.), Genus Dryopteris Adans. in Poland, s. 45-59. Polish Botanical Society, Institute of Plant Biology, University of Wrocław, Wrocław.

Woziwoda B. 2010. Dryopteris affinis (Dryopteridaceae) in Polish lowlands. - W: Z. MiReK \& A. NiKeL (red.), Rare, relict and endangered plants and fungi in Poland, s. 137-147. W. Szafer Institute of Botany, Polish Academy of Sciences, Kraków.

ZAJĄC A. \& ZająC M. (red.). 2001. Atlas rozmieszczenia roślin naczyniowych w Polsce. s. xii + 714. Nakładem Pracowni Chorologii Komputerowej Instytutu Botaniki Uniwersytetu Jagiellońskiego, Kraków.

ZAJĄC A. 1978. Założenia metodyczne „Atlasu rozmieszczenia roślin naczyniowych w Polsce”. - Wiadomości Botaniczne 22(3): 145-155.

Zarzycki W., Wilczek Z., Woźnica P., Folcik Ł., Lewandowska A. \& Gancarek M. 2015. Wpływ dębu czerwonego Quercus rubra L. na populacje paproci w różnych typach fitocenoz leśnych. - Sylwan 159(8): 658-665.

Dariusz TlaŁka (autor korespondencyjny), Os. nad Soła 4/19, 32-650, Kęty, Polska; e-mail: tlalkadariusz@gmail.com

Marek Podsiedlik, Zbiory Przyrodnicze, Wydziat Biologii, Uniwersytet im. Adama Mickiewicza w Poznaniu, ul. Uniwersytetu Poznańskiego 6, 61-614, Poznań, Polska; e-mail: podsiedlikmarek@amu.edu.pl

Wptynęto: 01.01.2020 r.; przyjęto do druku: 15.12.2020 r.

DOI: https://doi.org/10.35535/ffgp-2020-0041

\section{Rozmieszczenie, zasoby oraz zagrożenia Arenaria graminifolia (Caryophyllaceae) w Kampinoskim Parku Narodowym}

Arenaria graminifolia Schrad. (syn. Arenaria procera Spreng., Arenaria stenophylla Ledeb., Eremogone saxatilis (L.) Ikonn.), piaskowiec trawiasty, ma rozległy zasięg, ciągnący się od rzeki Wisły w Europie Centralnej po rzekę Lenę w Azji (Meusel i in. 1965; Plantarium 2021). Jest zaliczany do elementu holarktycznego, podelementu eurosyberyjskiego (ZAJĄC \& ZAJĄC 2009).

Arenaria graminifolia w Rosji został zamieszczony w regionalnych „czerwonych księgach" gatunków, m.in.: Udmurt (Tuganaev 2001), regionu Wołga (SENATOR i in. 2009), obwodu Wołogodzkiego (SusLova i in. 2013), okręgu Khanty-Mansiysk (VASIN 2003) oraz okręgu Vladimir (SEREGIN 2012). Europejskie populacje zagrożone wymarciem lub bliskie tego statusu stwierdzono w Austrii (FISCHER i in. 2008), na Słowacji (Eliáš i in. 2015), 